\title{
Synthesis of organically templated nanoporous tin (II/IV) phosphate for radionuclide and metal sequestration
}

\author{
Dawn M. Wellman*, Shas V. Mattigod, Kent E. Parker, Steve M. Heald, Chongmin Wang, and \\ Glen E. Fryxell \\ Pacific Northwest National Laboratory, Richland, WA 99352 USA. Fax: (509) 375-2017; Tel: (509) \\ 375-6936; E-mail: dawn.wellman@pnl.gov
}

This submission was created using the RSC ChemComm Template (DO NOT DELETE THIS TEXT) (LINE INCLUDED FOR SPACING ONLY - DO NOT DELETE THIS TEXT)

\begin{abstract}
Nanoporous tin (II/IV) phosphate materials, with spherical morphology, have been synthesized using eetyltrimethylammonium ehloride $\left(\mathrm{CH}_{3}\left(\mathrm{CH}_{2}\right)_{16} \mathrm{~N}\left(\mathrm{CH}_{3}\right)_{3} \mathrm{Cl}\right)$ as the surfactant. The structure of the material is stable at $500^{\circ} \mathrm{C}$; however, partial oxidation of the material occurs with redox conversion of $\mathrm{Sn}^{2+}$ to $\mathrm{Sn}^{4+}$, resulting in a mixed Sn(II)/ Sn(IV) material.
\end{abstract}

Nanoporous materials offer an efficient way of selectively sequestering many types of metals and radionuclides in a very small volume. The high surface area of a nanoporous structure enhances mass transfer in sequestration applications and enables ions to be highly coneentrated in a very small volume of material. Operations related to nuclear energy and weapons production have produced significant quatnities of radioactive waste over the last half century. The waste is targeted to be processed and buried in a deep geological repository (e.g. Yucea Mountain, Nevada). The current proposal is to include "getter materials" with this waste in order to sequester any radionuclides that might leach from the wasteforms. Of particular interest in this regard are the long-lived actinide species (e.g. $\mathrm{Pu}, \mathrm{Am}, \mathrm{Np}$, etc.) and the anions (e.g. pertechnetate, iodide, etc.). Getter materials must be able to survive long-term exposure to elevated temperatures $\left(>150^{\circ} \mathrm{C}\right)$ and moderately high radiation fluxes. The frailty of organic components towards radiolytic degradation precludes their use for either structure or function in the final getter material.

Over the last decade, metal phosphates have been extensively studied due to their potential use in catalysis, ion-exchange, and phase separation ${ }^{12}$. Since the first open-framework tin phosphates were prepared nearly 15 years ago, there has been interest in the structural flexibility of tin phosphates crystallizing in one-dimensional, three-dimensional, or layered structures ${ }^{3-12}$. Open-framework tin phosphates have been prepared by direct precipitation ${ }^{10}$ and by incorporating organic amines into the crystal lattice ${ }^{39,11,12}$. Surfactant-templated, open-framework tin phosphates have been reported using structure directing amine compounds including ethylenediamine ${ }^{4,12}, 1,6$-diaminohexane ${ }^{5}$, 1,2-diaminopropane", 1,8-diaminooctane, and 1,4diaminobutane ${ }^{6}$. Only recently, however, has a nanoporous tin (IV) phosphate been reported, and, to date, this is the only known report of a nanoporous tin phosphate ${ }^{13}$. The cationic quaternary ammonium salt $\mathrm{CH}_{3}\left(\mathrm{CH}_{2}\right)_{14} \mathrm{~N}\left(\mathrm{CH}_{3}\right)_{3} \mathrm{Br}$ was used as the surfactant. The use of CTAB as surfactant resulted in surface areas of $230 \mathrm{~m}^{2} / \mathrm{g}$, and pore sizes of $35-38 \mathrm{~A}$. Although the pore size was reduced from 39 to $35 \AA$, the structure was stable following calcination.

The goal of this study was to produce a similarly stable, mesoporous solid using tin (II) as the starting material to produce a material capable of sequestering redox sensitive species such as pertechnetate, neptunium, chromium, iodide, ete.

Electronic Supplementary Information (ESI) available: [details of any supplementary information available should be included here]. See hitp://www.rse.org/suppdata/ce/b0/b000000a/
The large pores afforded with quaternary ammonium surfactants and the high surface area of a nanoporous structure are valuable features for enhanced mass transfer in sequestration applications. This communication summarizes efforts to make a nanoporous tin(II) phosphate phase.

The synthesis method consists of preparing $200 \mathrm{~mL}$ of 6.87 mmol CTAC, $\mathrm{CH}_{3}\left(\mathrm{CH}_{2}\right)_{14} \mathrm{~N}\left(\mathrm{CH}_{3}\right)_{3} \mathrm{Cl}$, in deionized water. The solution is acidified with $0.626 \mathrm{~mL}$ of concentrated phosphoric acid. A concentrated solution of $15.222 \mathrm{~g}$ stannous chloride was dissolved in $100 \mathrm{~mL}$ hydrochloric acid. $2.5 \mathrm{~mL}$ of $\mathrm{SnCl}_{2} / \mathrm{HCl}$ solution was added with stirring at room temperature to the acidified surfactant. The solution stirred for 30 minutes at room temperature and was place in an oven at $65^{\circ} \mathrm{C}$ for $48-72$ hours. The synthetic material was collected via vacuum filtration using a $0.45 \mu \mathrm{m}$ filter, washed with deionized water and dried under ambient conditions. Chemical analysis of the synthetic material indicates the structure is composed of Sn:P:O with a ratio of 1:1:5

Calcination of the as-synthesized material at $500^{\circ} \mathrm{C}$ produced a material with a surface area of $262 \mathrm{~m}^{2} / \mathrm{g}$. The XRD pattern of the surfactant- $\mathrm{SnPO}_{4}$ and calcined $\mathrm{SnPO}_{4}$ are shown in Fig. 1 . The $d$ spacing of the 100 plane in surfactant- $\mathrm{SnPO}_{4}$ is $5.01 \mathrm{~nm}$, whereas after calcintation it was reduced to $4.62 \mathrm{~nm}$. Subjecting the nanoporous $\mathrm{SnPO}_{4}(\mathrm{NP}-\mathrm{SnPO})$ to high temperatures during ealcination seem to have little impact on pore size.

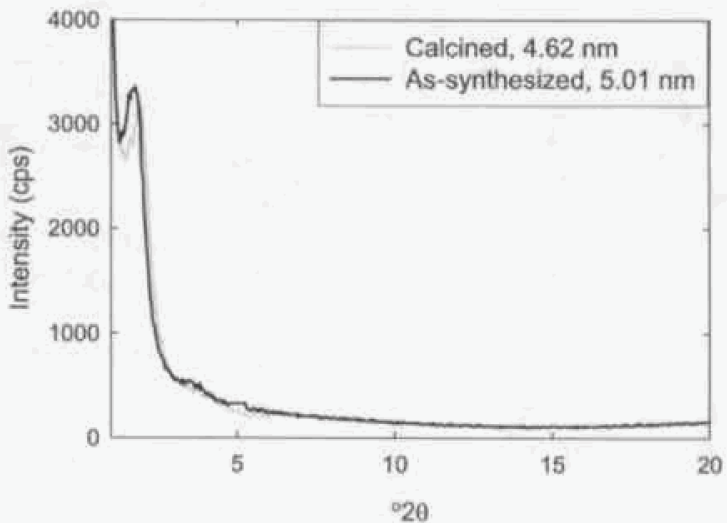

Figure 1. X-ray diffraction pattern for surfactant-SnPO, and ealcined $\mathrm{SnPO} 4$.

Selected-area electron diffraction analysis of a typical tin phosphate (NP-SNPO1) illustrates a completely amorphous structure (Figure 2a). Analyses with high-resolution transmission-electron microscopy (HR-TEM) revealed a spherical particle morphology approximately $150 \mathrm{~nm}$ across, with uniform pore distribution narrowly distributed around $2 \mathrm{~nm}$ (Figure $2 \mathrm{~b}$ ). It was also observed that directly precipitated NP. 
SNPO materials, in addition to being thermally stable $\left(500^{\circ} \mathrm{C}\right)$. are chemically stable over the entire $\mathrm{pH}$ range $(\mathrm{pH}=0$ to 14$)$.
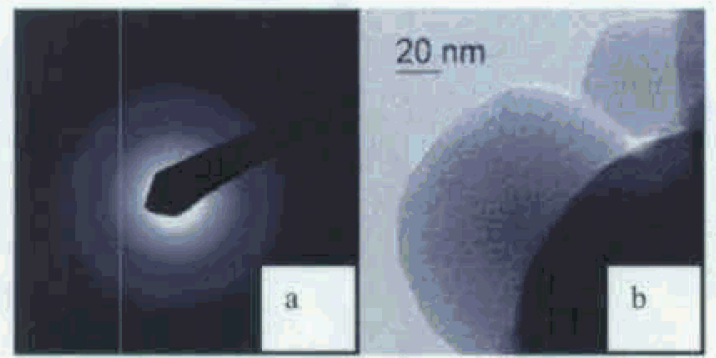

Figure 2. (a) Selected-area electron diffraction pattern indicating amorphous structure. (b) Nanoporous tin (II) phosphate with uniform pore distribution narrowly distributed around $2 \mathrm{~nm}$.

Preliminary batch contact studies have been conducted to assess the effectivness of NP-SnPO in sequestering redox sensitive metals and radionuclides, technetium(VII), neptunium(V), thorium(IV), and a toxie metal, chromium(VI). from aqueous matrices (Table 1). Equilibrium was achieved in less than an hour at a solution to solids ratio of 100 , therefore a batch contact time of 2 hours was used to insure that these values represent true equilibrium conditions. Under these conditions the nanoporous, calcined tin (II) phosphate removed $>95 \%$ of all contaminants investigated from solution. Distribution coefficients, $K_{d}$, are defined as a mass-weighted partition coefficient. $K_{d}$ values were typically $>10,000$ in groundwater. At a solution to solids ratio of 100, a $K_{d}$ value of 10,000 indicates that at equilibrium there was 100 times as much contaminant in the nanoporous metal phosphate phase as there was remaining in the supernantant solution.

Table 1. Affinity of NP-SnPO for Tc(VII), Np(V),

\begin{tabular}{|c|c|c|}
\hline \multicolumn{3}{|c|}{ Th(IV), and $\mathrm{Cr}$ (VI) } \\
\hline Sorbate & Test Matrix & $\mathrm{K}_{\mathrm{d}}(\mathrm{mL} / \mathrm{g})$ \\
\hline $\mathrm{Tc}(\mathrm{VII})$ & $0.002 \mathrm{M} \mathrm{NaHCO}_{3}$ & $>9.0 \times 10^{4}$ \\
\hline $\mathrm{Np}(\mathrm{V})$ & $0.002 \mathrm{M} \mathrm{NaHCO}_{3}$ & $>1.1 \times 10^{5}$ \\
\hline Th(IV) & DI Water & $>2.2 \times 10^{4}$ \\
\hline $\mathrm{Cr}(\mathrm{VI})$ & $0.002 \mathrm{M} \mathrm{NaHCO}_{3}$ & $>5.6 \times 10^{4}$ \\
\hline $\mathrm{Cr}(\mathrm{VI})$ & $\mathrm{GW}+0.02 \mathrm{M} \mathrm{Na}_{2} \mathrm{SO}_{4}$ & $>4.4 \times 10^{4}$ \\
\hline
\end{tabular}

Data obtained via X-Ray Absorption Near Edge Spectra/Extended X-Ray Absorption Fine Structure (XANES/EXAFS) elearly illustrate the sequestration of Te(VII). $\mathrm{Np}(\mathrm{V})$, and $\mathrm{Cr}(\mathrm{VI})$ with NP-SNPO occurs through redoxcoupled reactions with the target metals being reduced to their least soluble valence states, namely, $\mathrm{Tc}$ (IV), $\mathrm{Np}$ (IV), and $\mathrm{Cr}$ (III), with oxidation of $\mathrm{Sn}$ in NP-SnPO (Figure 3). Although lacking spectroseopic data, we surmise that Th(TV) adsorption on NP-SnPO is due to Lewis acid-base interaction with $\mathrm{PO}_{4}$ groups.

These nanoporous tin (II) phosphates exhibited significant promise as sorbent materials for anionic and redox sensitive metals and actinides. The detailed kinetic studies of these materials will be published in due course.

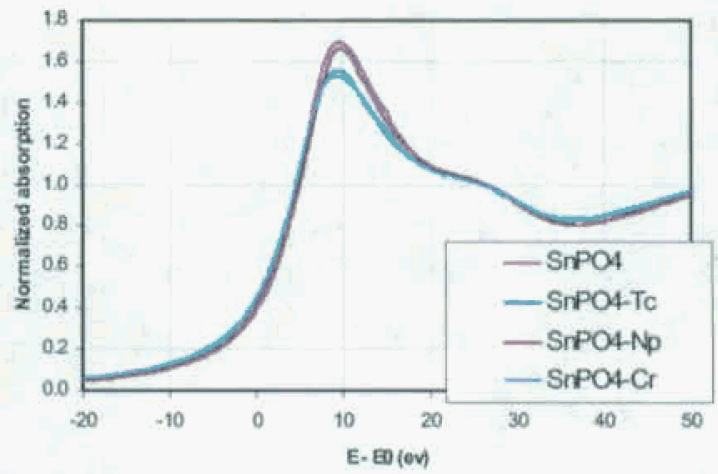

Figure 3. EXAFS spectra of NP-SnPO collected after batch sequestration tests with $\mathrm{Tc}(\mathrm{VII}), \mathrm{Np}(\mathrm{V})$, and $\mathrm{Cr}(\mathrm{VI})$. Data clearly illustrateate the oxidation of NP-SNPO with concurrent reduction of the target metal contaminant.

\section{Notes}

This research was supported by the U. S. Department of Energy (DOE), Office of Civilian Radioactive Waste Management. This work was performed at Pacific Northwest National Laboratories, which is operated for the DOE by Battelle Memorial Institute under contract DE AC05-76RLO 1830.

\section{References}

1. S. Polarz and B. Smarsly, J. Nanosci. Nanotech. 2002. 2, 581-612.

2. A. K. Cheetham, G. Ferey, and T. Loiseau, Angew. Chem. Int. Ed. 1999. 38, 3268-3292.

3. S. Natarajan, J. Solid State Chem. 1999. 149, 50.

4. S. Natarajan, M. P. Attfield, and A. K. Cheetham, Angew. Chem. Int. Ed. 1997. 36, 978-980.

5. S. Natarajan, S. Ayyappan, A. K. Cheetham, and C. N. R. Rao, Chemical Material 1998. 10, 1627-1631.

6. S. Natarajan and A. K. Cheetham, Chem. Comm, 1997. 1089-1090.

7. S. Natarajan and A. K. Cheetham, J. Solid State Chem. 1997. 134, 207-210.

8. S. Ayyappan, X. Bu, A. K. Cheetham, and C. N. R. Rao, Chem. Mater. 1998. 10, 3308.

9. S. Ayyappan, A. K. Cheetham, S. Natarajan, and C. N. R. Rao, J. Solid State Chem. 2000. 152, 207.

10. R. P. Bontchev and R. C. Moore, Solid State Sci. 2004. 6, 867-873.

11. C. Serre, A. Auroux, A. Gervasini, M. Hervieu, and G. Ferey, Angew. Chem. Int. Ed. 2002. 41, 1594.

12. C. Serre and G. Ferey, Chem, Comm. 2003, 1818 1819.

13. N. K. Mal, S. Ichikawa, and M. Fujiwara, Chem. Comm. 2002, 112-113. 